\title{
Availability of Emergency Drugs and Essential Equipment in Intensive Care Units in Hospitals of Ethiopia: A Multicenter Cross-Sectional Study
}

This article was published in the following Dove Press journal: Open Access Emergency Medicine

\author{
Metages Hunie $\mathbb{D}^{\prime}$ \\ Tiruwork Desse ${ }^{2}$ \\ Efrem Fenta (D) \\ Diriba Teshome (D) \\ Moges Gelaw $\mathbb{D}^{\prime}$ \\ Amanu Gashaw (D) $^{3}$ \\ 'Department of Anesthesia, School of \\ Medicine, College of Health Sciences, \\ Debre Tabor University, Debre Tabor, \\ Ethiopia; ${ }^{2}$ Department of Internal \\ Medicine, School of Medicine, College of \\ Health Sciences, Debre Tabor University, \\ Debre Tabor, Ethiopia; ${ }^{3}$ Department of \\ Anesthesia, School of Medicine, College \\ of Health Science, Hawassa University, \\ Hawassa, Sidama, Ethiopia
}

Correspondence: Metages Hunie Department of Anesthesia, School of Medicine, College of Health Sciences, Debre Tabor University, PO. Box: 272, Debre Tabor, Ethiopia

Email huniemetages@gmail.com
Purpose: Emergency drugs and essential equipment are important to successfully manage patients in the intensive care unit (ICUs). The absence of these emergency drugs and essential equipment might result in mortality and morbidity which is more compounded in resource-limited settings. This study aims to assess the availability of emergency drugs and essential equipment in ICUs in hospitals in Ethiopia.

Materials and Methods: A cross-sectional descriptive study design was employed in the intensive care unit of nine Amhara regional state hospitals in Ethiopia. This study was done from August 01, 2020, to September 01, 2020. The data were collected using a structured questionnaire, which were adopted from the Emergency Medicine Society of South Africa (EMSSA) guidelines. Tables and narration were used to describe results.

Results: There were deficiencies of essential emergency items particularly in the pediatrics domain, devices to confirm tracheal intubation and equipment for managing difficult intubation. Emergency drugs like adrenaline, salbutamol puff, atropine, aspirin, furosemide, hydrocortisone, insulin, lidocaine, and medical oxygen were available in all ICUs, whereas amiodarone, sodium bicarbonate, glucagon, ipratropium nebulization, thiamine were not available in all ICUs.

Conclusions and Recommendations: There were considerable deficiencies in emergency drugs and essential equipment. Based on our findings, we recommend to develop standardized checklists, regular audits, and healthcare personnel awareness program to improve checking, maintaining, restocking, and repairing the equipment in the emergency trolley.

Keywords: emergency drugs, essential equipment, intensive care unit, Ethiopia

\section{Introduction}

Emergency drugs and essential equipment in ICUs are important to successfully manage patients. A delay in inadequate response to an emergency may adversely affect the outcome. ${ }^{1,2}$ Early access to these emergency drugs and essential equipment is important in an increased survival rate of our victims. ${ }^{3}$

Having minimum recommended standards of essential and emergency equipment remains the cornerstone therapy for managing life-threatening conditions. ${ }^{4}$ The Emergency Medicine Society of South Africa (EMSSA) guideline recommends the availability of essential equipment and emergency drugs like devices to open and protect the airway, devices to confirm tracheal intubation, equipment for managing difficult intubation, devices to deliver oxygenation and ventilation, equipment to 
diagnose and treat cardiac arrhythmias, devices to gain vascular access, equipment for monitoring of breathing and circulation, emergency drugs, and intravenous fluids should available. ${ }^{5}$ Standardization of equipment, drugs, and emergency trolley components has been shown to improve and aid familiarity. ${ }^{6-10}$

The organized emergency trolleys provide structure, saves time, and decrease confusion in an otherwise possible chaotic situation. Every effort should be made to be able to streamline the restocking of used or missing items required on the emergency trolley. ${ }^{11-15}$

Ethiopia is one of the countries with inadequate health care facilities, equipment, human power resource, and emergency trolley guidelines. ${ }^{16-21}$ Hospital ICUs should have immediate access to the emergency trolley. The trolley needs regular checking, maintenance, and replacement of equipment. ${ }^{13,22-24}$

Studies on emergency drugs and equipment preparedness in ICUs are limited in developing countries like Ethiopia. This study aims to assess the availability of emergency drugs and essential equipment in ICUs in hospitals in Ethiopia.

\section{Materials and Methods}

\section{Study Setting, Design, and Period}

Amhara region is one of the regional states in Ethiopia. The region has eight Comprehensive Specialized Hospitals (Debre Tabor, University of Gondar, Felege Hiwot, Tibebe Ghion, Debre Berhan, Dessie, Woldia, and Debre Markos) and Injibara General Hospital with ICU services. A descriptive cross-sectional study design was used from August 01 to September 01, 2020.

\section{Sampling Technique}

All hospitals giving ICU services were surveyed for the availability of emergency drugs and essential equipment.

\section{Data Collection Technique}

Data were collected by using the EMSSA checklist which consists of the availability of emergency drugs, essential equipment, and intravenous fluids required for resuscitation during the study period by senior anesthetists in each Hospital.

\section{Data Analysis}

Data were manually checked for completeness and then coded and entered into SPSS version 20 computer program for analysis. Descriptive statistics were used to summarize by frequencies, and tables were used to present the data.

\section{Data Quality Control and Assurance}

After training was given to data collectors, data were collected and properly filled in the prepared format. Throughout the study period, data collection was supervised by the principal investigator. The investigator crosschecked for completeness and consistency of data.

\section{Results}

\section{The Availability of Essential Equipment Devices to Open and Protect the Airway}

When assessing the items in the devices to open and protect the airway, all Amhara regional hospital's ICUs were found to have a laryngoscope handle and adult blade. There was no pediatric blade at the University of Gondar in both medical and surgical ICUs. There were no nasopharyngeal airways in all hospitals (Table 1).

\section{Devices to Confirm Tracheal Intubation}

Esophageal detector device and end-tidal carbon dioxide monitoring including a single use of colorimetric devices were not found at all sites.

\section{Equipment for Managing Difficult Intubation}

Equipment used for managing difficult airways (adult introducers, Magill's forceps, gum elastic bougie, and pediatric introducers) were inadequately found in Amhara regional state hospitals except for Woldia Comprehensive Specialized Hospital and Tibebe Ghion Comprehensive Specialized Hospital.

\section{Devices to Deliver Oxygenation and Ventilation}

Bag-Mask ventilation devices with an oxygen reservoir, oxygen supply with flow regulator, and different facemasks to deliver oxygen and ventilate patients were available in all study sites. However, pediatric or neonatal mask ventilation devices were not found in the University of Gondar and Dessie Comprehensive Specialized Hospitals. A nebulizer mask was not available in all ICUs.

\section{Equipment to Diagnose and Treat Cardiac Arrhythmias}

The cardiac arrest board was not available in all ICUs. A defibrillator is available in all hospitals except in Dessie Comprehensive Specialized Hospital.

\section{Devices to Gain Vascular Access}

Intravenous administration sets including blood administration and high flow sets, all gauge IV cannulas, and all types of syringes were available in all ICUs except for 14-guage, 
Table I Availability of Devices Used to Open and Protect the Airway in ICUs of Amhara Regional State Hospitals of Ethiopia, from August 0 I to September 0I, 2020

\begin{tabular}{|c|c|c|c|c|c|c|c|c|c|}
\hline \multirow{2}{*}{$\begin{array}{l}\text { Devices Used to Open and } \\
\text { Protect the Airway }\end{array}$} & \multicolumn{9}{|c|}{ Hospitals in Amhara Regional State with ICU Services } \\
\hline & DTCSH & FHCSH & TGCSH & IGH & DMCSH & DBCSH & UOGCSH & WCSH & DCSH \\
\hline Laryngoscope set: handle with adult & $\sqrt{ }$ & $\sqrt{ }$ & $\sqrt{ }$ & $\sqrt{ }$ & $\sqrt{ }$ & $\sqrt{ }$ & $\sqrt{ }$ & $\sqrt{ }$ & $\sqrt{ }$ \\
\hline $\begin{array}{l}\text { Laryngoscope set: pediatric blades, } \\
\text { spare bulbs \& spare batteries }\end{array}$ & $\sqrt{ }$ & $\sqrt{ }$ & $\sqrt{ }$ & $\sqrt{ }$ & $\sqrt{ }$ & $\sqrt{ }$ & $\times$ & $\sqrt{ }$ & $\sqrt{ }$ \\
\hline $\begin{array}{l}\text { Tracheal tubes: un-cuffed (sizes } \\
2.5-5.5 \mathrm{~mm} \text { ) }\end{array}$ & $x$ & $x$ & $x$ & $x$ & $\times$ & $x$ & $\times$ & $\times$ & $x$ \\
\hline ETTs cuffed (sizes $3.0-8.5 \mathrm{~mm}$ ) & $\sqrt{ }$ & $\sqrt{ }$ & $\sqrt{ }$ & $\sqrt{ }$ & $\sqrt{ }$ & $\sqrt{ }$ & $\times$ & $\sqrt{ }$ & $\sqrt{ }$ \\
\hline Water-soluble lubricant/KY jelly & $\sqrt{ }$ & $\sqrt{ }$ & $\sqrt{ }$ & $\sqrt{ }$ & $\sqrt{ }$ & $\sqrt{ }$ & $\sqrt{ }$ & $\sqrt{ }$ & $\sqrt{ }$ \\
\hline $10 \mathrm{~mL}$ syringe & $\sqrt{ }$ & $\sqrt{ }$ & $\sqrt{ }$ & $\sqrt{ }$ & $\sqrt{ }$ & $\sqrt{ }$ & $\sqrt{ }$ & $\sqrt{ }$ & $\sqrt{ }$ \\
\hline $\begin{array}{l}\text { Tape or equivalent to tying tube in } \\
\text { place }\end{array}$ & $\sqrt{ }$ & $\sqrt{ }$ & $\sqrt{ }$ & $\sqrt{ }$ & $\sqrt{ }$ & $\sqrt{ }$ & $\sqrt{ }$ & $\sqrt{ }$ & $\sqrt{ }$ \\
\hline Oropharyngeal airways size $000-5$ & $\sqrt{ }$ & $\sqrt{ }$ & $\sqrt{ }$ & $\sqrt{ }$ & $\sqrt{ }$ & $\sqrt{ }$ & $\sqrt{ }$ & $\sqrt{ }$ & $\sqrt{ }$ \\
\hline Nasopharyngeal airways size $3-7$ & $\times$ & $\sqrt{ }$ & $x$ & $x$ & $x$ & $x$ & $x$ & $x$ & $x$ \\
\hline
\end{tabular}

Notes: ${ }^{\times}$not available, $\sqrt{ }$ available.

Abbreviations: DTCSH, Debre Tabor Comprehensive Specialized Hospital; FHCSH, Felege Hiwot Comprehensive Specialized Hospital; TGCSH, Tibebe Gihon Comprehensive Specialized Hospital; IGH, Injera General Hospital; DCSH, Debre Markos Comprehensive Specialized Hospital; DBCSH, Debre Birhan Comprehensive Specialized Hospital; UOGCSH, University of Gondar Comprehensive Specialized Hospital; WCSH, Woldia Comprehensive Specialized Hospital; DCSH, Dessie Comprehensive Specialized Hospital.

16-gauge IV cannula, and 50-mL syringe at Debre Tabor Comprehensive Specialized Hospital. The intraosseous and bone marrow needles were not found in all ICUs except for Felegehiwot Comprehensive Specialized Hospital.

\section{Equipment for Monitoring of Breathing and Circulation}

Stethoscope, pulse oximeter with adult and pediatrics probes, non-invasive blood pressure monitoring, collection tubes for investigation, and appropriate hardware tubes and catheters were available in all hospitals. Thermometers were not found in Felege Hiwot, Dessie, and Debre Markos Comprehensive Specialized Hospitals.

\section{The Availability of Emergency Drugs}

Adrenaline, salbutamol puff, atropine, furosemide, insulin, lidocaine, and medical oxygen were available in all ICUs. Amiodarone, sodium bicarbonate, glucagon, ipratropium nebulization, thiamine were not available in all ICUs (Table 2).

\section{Intravenous Solutions}

Ringer lactate, $0.9 \%$ sodium chloride, and $40 \%$ glucose were found in all ICUs, but there were no $10 \%$ dextrose, dextrose $50 \%$, and appropriate pediatric solutions in all hospitals.

\section{Discussion}

This study describes the availability of essential equipment and emergency drugs in ICUs in hospitals of Ethiopia.
ICU should be adequately prepared for managing lifethreatening emergencies to avoid medical mishaps. ${ }^{25}$ The preparedness of the ICU based on evidence recommendation is of paramount importance in improving the outcome of the ICU patients. Patients who are admitted to the ICU have a narrow safety margin due to inadequate availability of essential equipment and emergency drugs, which could be a double bunder for resource-limited settings. ${ }^{26}$

The EMSSA guideline checklist consists of three main parts, which required essential equipment, emergency drugs, and intravenous fluids required on an emergency trolley are implemented at specific time-points during resuscitation. $^{5}$

The findings of our study show that the availability of emergency drugs and essential equipment were found to be generally inadequate. Devices to confirm tracheal intubation, equipment for managing difficult intubation were not adequately available. Emergency drugs like adrenaline, salbutamol puff, atropine, aspirin, furosemide, hydrocortisone, insulin, lidocaine, and medical oxygen were available in all intensive care units, whereas amiodarone, sodium bicarbonate, glucagon, ipratropium nebulization, thiamine were not available in all ICUs.

Un-cuffed tracheal tube, nasopharyngeal airways, intraosseous needles, amiodarone, sodium bicarbonate, glucagon, ipratropium nebulization, thiamine dose emergency equipment and drugs are not readily available during emergency management and resuscitations in ICUs. 
Table 2 Availability of Emergency Drugs in ICUs of Amhara Regional State Hospitals in Ethiopia from August 01 to September 0I, 2020

\begin{tabular}{|c|c|c|c|c|c|c|c|c|c|}
\hline \multirow[t]{2}{*}{ Emergency Drugs } & \multicolumn{9}{|c|}{ Hospitals in Amhara Regional State with ICU Services } \\
\hline & DTCSH & FHCSH & TGCSH & IGH & DMCSH & DBCSH & UOGCSH & WCSH & DCSH \\
\hline Adrenaline & $\sqrt{ }$ & $\sqrt{ }$ & $\sqrt{ }$ & $\sqrt{ }$ & $\sqrt{ }$ & $\sqrt{ }$ & $\sqrt{ }$ & $\sqrt{ }$ & $\sqrt{ }$ \\
\hline Amiodarone & $x$ & $\times$ & $\times$ & $\times$ & $x$ & $\times$ & $x$ & $x$ & $\times$ \\
\hline $\begin{array}{l}\text { Antibiotics (range depends on local } \\
\text { circumstances) }\end{array}$ & $\sqrt{ }$ & $\sqrt{ }$ & $\sqrt{ }$ & $\sqrt{ }$ & $\sqrt{ }$ & $\sqrt{ }$ & $\sqrt{ }$ & $\sqrt{ }$ & $\sqrt{ }$ \\
\hline Antihistamine (eg promethazine) & $\times$ & $\sqrt{ }$ & $\sqrt{ }$ & $\sqrt{ }$ & $\sqrt{ }$ & $\times$ & $\times$ & $\sqrt{ }$ & $\sqrt{ }$ \\
\hline Aspirin & $\sqrt{ }$ & $\sqrt{ }$ & $\sqrt{ }$ & $\sqrt{ }$ & $\sqrt{ }$ & $\sqrt{ }$ & $\sqrt{ }$ & $\sqrt{ }$ & $\sqrt{ }$ \\
\hline Atropine & $\sqrt{ }$ & $\sqrt{ }$ & $\sqrt{ }$ & $\sqrt{ }$ & $\sqrt{ }$ & $\sqrt{ }$ & $\sqrt{ }$ & $\sqrt{ }$ & $\sqrt{ }$ \\
\hline $\begin{array}{l}\text { Beta stimulant nebulisation } \\
\text { (salbutamol) }\end{array}$ & $\sqrt{ }$ & $\sqrt{ }$ & $\sqrt{ }$ & $\sqrt{ }$ & $\sqrt{ }$ & $\sqrt{ }$ & $\sqrt{ }$ & $\sqrt{ }$ & $\sqrt{ }$ \\
\hline Calcium chloride $10 \%$ & $\sqrt{ }$ & $x$ & $x$ & $x$ & $x$ & $x$ & $x$ & $x$ & $x$ \\
\hline Furosemide & $\sqrt{ }$ & $\sqrt{ }$ & $\sqrt{ }$ & $\sqrt{ }$ & $\sqrt{ }$ & $\sqrt{ }$ & $\sqrt{ }$ & $\sqrt{ }$ & $\sqrt{ }$ \\
\hline Glucagon & $\times$ & $\times$ & $\times$ & $\times$ & $\times$ & $\times$ & $\times$ & $\times$ & $\times$ \\
\hline Hydrocortisone & $\sqrt{ }$ & $\sqrt{ }$ & $\sqrt{ }$ & $\sqrt{ }$ & $\sqrt{ }$ & $\sqrt{ }$ & $\sqrt{ }$ & $\sqrt{ }$ & $\sqrt{ }$ \\
\hline Insulin & $\sqrt{ }$ & $\sqrt{ }$ & $\sqrt{ }$ & $\sqrt{ }$ & $\sqrt{ }$ & $\sqrt{ }$ & $\sqrt{ }$ & $\sqrt{ }$ & $\sqrt{ }$ \\
\hline $\begin{array}{l}\text { Ipratropium nebulization and inhaler } \\
\text { with a spacer }\end{array}$ & $x$ & $x$ & $x$ & $x$ & $x$ & $\times$ & $x$ & $x$ & $x$ \\
\hline Lignocaine IV & $\sqrt{ }$ & $\sqrt{ }$ & $\sqrt{ }$ & $\sqrt{ }$ & $\sqrt{ }$ & $\sqrt{ }$ & $\sqrt{ }$ & $\sqrt{ }$ & $\sqrt{ }$ \\
\hline Magnesium & $\sqrt{ }$ & $\sqrt{ }$ & $\sqrt{ }$ & $\times$ & $\sqrt{ }$ & $x$ & $x$ & $\sqrt{ }$ & $\sqrt{ }$ \\
\hline Medical oxygen & $\sqrt{ }$ & $\sqrt{ }$ & $\sqrt{ }$ & $\sqrt{ }$ & $\sqrt{ }$ & $\sqrt{ }$ & $\sqrt{ }$ & $\sqrt{ }$ & $\sqrt{ }$ \\
\hline Potassium chloride & $\sqrt{ }$ & $\sqrt{ }$ & $\sqrt{ }$ & $\sqrt{ }$ & $\sqrt{ }$ & $\times$ & $\times$ & $\times$ & $\times$ \\
\hline Naloxone & $x$ & $x$ & $\sqrt{ }$ & $\times$ & $x$ & $x$ & $x$ & $\sqrt{ }$ & $x$ \\
\hline Sodium bicarbonate $8.5 \%$ & $x$ & $\times$ & $\times$ & $\times$ & $x$ & $x$ & $\times$ & $x$ & $x$ \\
\hline Thiamine & $x$ & $x$ & $x$ & $x$ & $x$ & $x$ & $x$ & $x$ & $x$ \\
\hline
\end{tabular}

Notes: ${ }^{\times}$not available, $\sqrt{ }$ available.

Abbreviations: DTCSH, Debre Tabor Comprehensive Specialized Hospital; FHCSH, Felege Hiwot Comprehensive Specialized Hospital; TGCSH, Tibebe Gihon Comprehensive Specialized Hospital; IGH, Injera General Hospital; DCSH, Debre Markos Comprehensive Specialized Hospital; DBCSH, Debre Birhan Comprehensive Specialized Hospital; UOGCSH, University of Gondar Comprehensive Specialized Hospital; WCSH, Woldia Comprehensive Specialized Hospital; DCSH, Dessie Comprehensive Specialized Hospital.

The reason we feel is the lack of stakeholders' coordination in setting short- and long-term goals to avail these essential equipment and drugs.

Unpredictable difficult intubation in an ICU is an event that requires extensive preparedness of clinicians in terms of essential equipment, ie device to confirm tracheal intubation and managing difficult intubation to overcome it and its consequences. Our study reveals almost all of the ICUs are lack of a device to confirm tracheal intubation and managing difficult intubation. Generally, the availability of essential emergency equipment was found to be inadequate. There were considerable deficiencies in essential emergency items, which were in line with the study done by Tim et al, Eley et al, and Rajeswaran et al, respectively. ${ }^{23,27,28}$

\section{Conclusions}

The availability of essential emergency equipment and drugs was found to be generally inadequate. There were considerable deficiencies of essential emergency items particularly in the pediatrics domain, devices to confirm tracheal intubation, equipment for managing difficult intubation. This may negatively impact the resuscitative efforts at all levels within ICU.

\section{Recommendations}

We recommend carrying out regular health care personnel awareness programs to improve checking, maintaining, restocking, and repairing the equipment in the emergency trolley. And also, we recommend for the administrators of the hospitals to respond to the requests and fulfill the requirements of the essential equipment and emergency drugs.

\section{Limitations}

The study described emergency supplies within a single snapshot of time. Many confounding factors could be 
attributed to the results including addressing the issue of previously ordered stock having arrived and stock ordered but not having arrived.

\section{Abbreviations}

EMSSA, Emergency Medicine Society of South Africa, ETTs, endotracheal tubes, Iv, intravenous, ICU, intensive care unit.

\section{Ethical Consideration}

Ethical clearance was obtained from Debre Tabor University Ethical Review Committee, while a letter of permission was secured from each hospital's administrator and ICU head.

\section{Acknowledgment}

Debre Tabor University.

\section{Author Contributions}

All authors made a significant contribution to the work reported, whether that is in the conception, study design, execution, acquisition of data, analysis, and interpretation, or in all these areas; took part in drafting, revising, or critically reviewing the article; gave final approval of the version to be published; have agreed on the journal to which the article has been submitted; and agree to be accountable for all aspects of the work.

\section{Funding}

There is no funding to report.

\section{Disclosure}

The authors report no conflicts of interest for this work.

\section{References}

1. Wallis LA, Guly HR. Improving care in accident and emergency departments. BMJ. 2001;323(7303):39-42.

2. Travers AH, Rea TD, Bobrow BJ, et al. Part 4: CPR overview: 2010 American Heart Association guidelines for cardiopulmonary resuscitation and emergency cardiovascular care. Circulation. 2010;122(18_suppl_3): S676-S84. doi:10.1161/CIRCULATIONAHA.110.970913

3. Soar J, Nolan JP, Böttiger BW, et al. European resuscitation council guidelines for resuscitation 2015: section 3. Adult advanced life support. Resuscitation. 2015;95:100-147. doi:10.1016/j.resuscitation.2015.07.016

4. Deakin CD, Nolan JP, Soar J, et al. European resuscitation council guidelines for resuscitation 2010 section 4. Adult advanced life support. Resuscitation. 2010;81(10):1305. doi:10.1016/j.resuscitation.2010.08.017

5. Wallis PL. Emergency medicine society of south africa practice guideline em006 resuscitation trolley equipment. Emerg Med Soc South Afr. 2008.
6. Seethala RR, Esposito EC, Abella BS. Approaches to improving cardiac arrest resuscitation performance. Curr Opinion Crit Care. 2010;16(3):196-202. doi:10.1097/MCC.0b013e328338c121

7. Rousek JB, Hallbeck MS. Improving medication management through the redesign of the hospital code cart medication drawer. Human Factors. 2011;53(6):626-636. doi:10.1177/ 0018720811426427

8. Dyson E, Smith GB. Common faults in resuscitation equipmentguidelines for checking equipment and drugs used in adult cardiopulmonary resuscitation. Resuscitation. 2002;55(2):137-149. doi:10.1016/S0300-9572(02)00169-7

9. J-F B, Scharr K, Marquis C, et al. Reevaluation of emergency drug management in a tertiary care mother-child hospital. Hospital Pharmacy. 2009;44(7):584-593.

10. Adamson K. Are We Ready for an Emergency. Stellenbosch: Stellenbosch University; 2012.

11. Tsima BM, Rajeswaran L, Cox M. Assessment of cardiopulmonary resuscitation equipment in resuscitation trolleys in district hospitals in Botswana: a cross-sectional study. Afr J Prim Health Care Fam Med. 2019;11(1):1-7. doi:10.4102/phcfm.v11i1.2029

12. Maritz D, Hodkinson P, Wallis L. Identification of performance indicators for emergency centres in South Africa: results of a Delphi study. International Journal of Emergency Medicine. 2010;3(4):341-349. doi:10.1007/s12245-010-0240-6

13. Manetti BKS, Amukugo HJ, Shilunga AP Emergency trolley's contents and records: audit study at maternity sections, state hospitals, Windhoek, Namibia. 2018.

14. Daftary RK, Murray BL, Reynolds TA. Development of a simple, practice-based tool to assess quality of paediatric emergency care delivery in resource-limited settings: identifying critical actions via a Delphi study. BMJ Open. 2018;8(8):e021123. doi:10.1136/bmjopen-2017-021123

15. Broccoli MC, Moresky R, Dixon J, et al. Defining quality indicators for emergency care delivery: findings of an expert consensus process by emergency care practitioners in Africa. BMJ Global Health. 2018;3:1. doi:10.1136/bmjgh-2017-000479

16. Mohammed MS, Tumebo AA. The status of emergency medicine in Ethiopia, challenges and opportunities. Ethiop Med J. 2018;56:2.

17. Germa F, Bayleyegn T, Kebede T, Ducharme J, Bartolomeos K. Emergency medicine development in Ethiopia: challenges, progress and possibilities. Afr J Emerg Med. 2013;3(1):3-9. doi:10.1016/j. afjem.2012.08.005

18. Calvello EJ, Tenner AG, Broccoli MC, et al. Operationalising emergency care delivery in sub-Saharan Africa: consensus-based recommendations for healthcare facilities. Emerg Med J. 2016;33 (8):573-580. doi:10.1136/emermed-2015-204994

19. Broccoli MC, Pigoga JL, Nyirenda M, Wallis L, Hynes EC. Essential medicines for emergency care in Africa. Afr J Emerg Med. 2018;8 (3):110-117.

20. Bae C, Geduld H, Wallis LA, Reynolds T. Professional needs of young emergency medicine specialists in Africa: results of a South Africa, Ethiopia, Tanzania, and Ghana survey. Afr J Emerg Med. 2016;6(2):94-99. doi:10.1016/j.afjem.2016.02.005

21. Abdelwahab R, Yang H, Teka HG. A quality improvement study of the emergency centre triage in a tertiary teaching hospital in northern Ethiopia. Afr J Emerg Med. 2017;7(4):160-166.

22. Vincent N. Timely Accessibility of Critical Resuscitation Supplies in the Emergency Department at Kigali University Teaching Hospital. 2019.

23. Rajeswaran L, Ehlers VJ. Audits of emergency trolleys' contents in selected hospitals in Botswana. Health SA Gesondheid (Online). 2012;17(1):1-7.

24. da Silva Oliveira EC, de Oliveira RC, Pereira da Silva F, Silva Nunes C. Standardization of Drugs in Emergency Trolleys in Intensive Care and Emergency Units. Revista De Enfermagem Referência. 2019;4:22. 
25. Perneger TV. The Swiss cheese model of safety incidents: are there holes in the metaphor? BMC Health Serv Res. 2005;5(1):71. doi:10.1186/1472-6963-5-71

26. Hanson CW, Deutschman CS, Anderson HL, et al. Effects of an organized critical care service on outcomes and resource utilization: a cohort study. Crit Care Med. 1999;27(2):270-274. doi:10.1097/ 00003246-199902000-00030
27. Eley V, Lloyd B, Scott J, Greenland K. Availability of Difficult Airway Equipment to Rural Anaesthetists in Queensland, Australia. 2008.

28. Baker T, Lugazia E, Eriksen J, Mwafongo V, Irestedt L, Konrad D. Emergency and critical care services in Tanzania: a survey of ten hospitals. BMC Health Services Research. 2013;13(1):140. doi:10.1186/1472-6963-13-140

\section{Publish your work in this journal}

The Open Access Emergency Medicine is an international, peerreviewed, open access journal publishing original research, reports, editorials, reviews and commentaries on all aspects of emergency medicine. The manuscript management system is completely online

Submit your manuscript here: https://www.dovepress.com/open-access-emergency-medicine-journal and includes a very quick and fair peer-review system, which is all easy to use. Visit http://www.dovepress.com/testimonials.php to read real quotes from published authors. 